\title{
Os Vínculos de Comprometimento e Entrincheiramento Presentes nas Organizaçóes Públicas
}

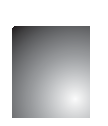

\author{
The Ties of Commitment and Entrenchment in Public \\ Organizations
}

\author{
Ana Paula Grillo Rodrigues \\ Professora Efetiva do Centro de Ciências da Administração e Sócioeconômicas, Universidade do Estado de Santa Catarina - \\ Florianópolis - SC - Brasil. E-mail: apgrodrigues@uol.com.br \\ Antônio Virgílio Bittencourt Bastos \\ Professor Efetivo da Universidade Federal da Bahia - Salvador - BA - Brasil. E-mail: antoniovirgiliobastos@gmail.com
}

\section{Resumo}

Esta pesquisa analisou a relação de vínculos de comprometimento, entrincheiramento e variáveis sociodemográficas estabelecidas entre servidores públicos e as organizações onde trabalham. O instrumento de coleta de dados foi um questionário contendo itens abertos e fechados incluindo questões referentes ao comprometimento e entrincheiramento organizacionais e dados sociodemográficos. A amostra contou com 400 trabalhadores de nove organizações públicas, situadas em Florianópolis. Os principais resultados apontaram servidores públicos mais comprometidos do que entrincheirados. Dentro deste resultado foram encontradas algumas peculiaridades relevantes, como: indivíduos casados, com filhos e alto grau de responsabilidade financeira, na sua maioria, foram caracterizados com nível de comprometimento e entrincheiramento altos. Percebeu-se, ainda, que quanto maior o nível educacional, maior o nível de entrincheiramento.

Palavras-chave: Comprometimento. Entrincheiramento. Organizações Públicas.

\begin{abstract}
This research examined the relationship of ties of commitment, entrenchment and sociodemographic variables established between public servants and the organizations where they work. The data collection instrument was a questionnaire containing items including open and closed questions regarding organizational commitment and entrenchment and sociodemographic data. The sample consisted of 400 employees from nine public organizations, located in Florianópolis. The main results showed public servants committed more than entrenched. Within this result so found some relevant peculiarities, such as married individuals with children and high degree of financial responsibility, mostly level were characterized with high commitment and entrenchment. It was noticed also that the higher the educational level, the greater the level of entrenchment.
\end{abstract}

Key words: Commitmnt. Entrenchment. Public Organizations. 


\section{INTRODUÇÃO}

O trabalho tem desempenhado um papel central na vida do ser humano. A subsistência, a socialização $e$ a identidade pessoal têm sido determinadas, dentre outros fatores, principalmente, pela inserção do indivíduo no mundo do trabalho que, ao longo da história, cada vez mais, significa sua atuação em contextos organizacionais em estreita interação com outras pessoas e sob um conjunto de normas e prescrições que definem papéis e atribuições a todos os atores. Diante da magnitude do tema, estudar o comportamento organizacional tem se tornado uma tarefa de crescente complexidade pelas inúmeras variáveis $e$ dimensões que possui e pelas mudanças que estão ocorrendo no mundo do trabalho e nas relações dos indivíduos com as organizações. Dentro desse vasto campo ou domínio de pesquisa, a questão do vínculo que o trabalhador desenvolve com vários aspectos do seu mundo de trabalho e, em especial, com a organização, tem recebido, historicamente, grande interesse da comunidade científica, quer pela centralidade deste fenômeno na vida organizacional, quer pelos impactos desse vínculo sobre o desempenho individual, grupal e organizacional.

$\mathrm{O}$ vínculo que une o indivíduo à organização é construído por meio de um processo de troca, tanto material quanto simbólica, no qual de um lado existe a organização com o sentido de sua existência, suas pressões ambientais, suas metas e objetivos a serem alcançados, seus modelos de gestão e, de outro, o indivíduo com suas expectativas e necessidades. Dessa interação, múltiplos vínculos podem emergir, com distintas consequências para os indivíduos e para as próprias organizações. O vínculo se concretiza de forma positiva para ambos os atores - indivíduo e organização - a partir do momento que as necessidades entre demandas sociais, exigências organizacionais $e$ desejos individuais convergem, fazendo com que se estabeleça um elo, principalmente, entre os dois últimos elementos, amparado e guiado pelo primeiro, que são as demandas apontadas pela sociedade.

Em razão da necessidade de fazerem confluir as necessidades sociais, organizacionais e individuais é importante que o indivíduo crie, com a organização, vínculos de forma a satisfazer estas demandas de maneira satisfatória.
O vínculo entre indivíduo e organização pode ser estudado dentro de muitas perspectivas, algumas mais próximas da perspectiva unidimensional de Becker (1960) e Mowday et al. (1982), e outros da perspectiva multidimensional de O'Reilly e Chatman (1986), Meyer e Allen (1996), Medeiros et al. (1999) e Rego (2003). Para Menezes (2009), as organizações não podem ser analisadas como entidades monolíticas, desconsiderando atitudes e comportamentos que resultam em identificações e apegos por parte do trabalhador. De acordo com Siqueira e Gomide (2004), os vínculos apresentados pelo indivíduo no ambiente de trabalho ajudarão a estabelecer e, ao mesmo tempo, serão estabelecidos pelos diversos níveis de ligação, identificação, internalização de normas e valores adotados pelo sistema.

A qualidade do vínculo pode ser considerada um reflexo, não apenas de valores intrínsecos e atitudinais do indivíduo, mas também, como uma resposta à cultura da organização. Existem diferenças significativas quanto à cultura de organizações públicas e privadas. As organizações públicas trazem algumas características culturais que as tornam peculiares. Além da estrutura com características mais burocráticas e hierarquizadas, as organizações públicas trazem características de cunho comportamental que merecem ser destacadas.

Carbone (2000) afirma que a administração pública apresentava, até o começo do milênio, alguns traços comportamentais bastante característicos como: desconhecimento, desinteresse e permeabilidade excessiva a pressões vindas do ambiente externo.

Do ponto de vista da gestão, Ckagnazaroff (2002) faz uma comparação entre gestor do setor público e o gestor do setor privado destacando fatores como a inovação, a motivação, a estabilidade e o poder. Quanto à inovação, os gestores públicos são considerados lentos se comparados ao gestor do setor privado, devido à ênfase dada aos procedimentos preestabelecidos, limitando o gestor a um espectro reduzido de opçóes de soluções. A motivação é determinada pela ação diretamente relacionada com a perspectiva do alcance dos resultados esperados pelo indivíduo (BERGUE, 2010). Diante da missão de atuar em direção ao interesse público, a motivação do gestor público nem sempre é compatível com os interesses do Estado, fazendo com que muitas vezes os resultados de suas ações sejam frustrantes, diminuindo o nível da sua motivação. 
Quanto à estabilidade, Pires e Macedo (2006) destacam a descontinuidade administrativa na gestão pública. Os autores se referem à existência de projetos e de trabalhadores do serviço público que não têm estabilidade e mudam a cada mandato de governo, caracterizados como um corpo não permanente. Essa descontinuidade manifestada pela atuação de trabalhadores sem estabilidade reflete no desempenho de servidores que, independente do governo que atuam, se mantêm na organização pela estabilidade, trazendo algumas consequências como: projetos de curto prazo, para que possam ser concluídos no mesmo mandato para ter retorno político; duplicação de projetos; e conflitos de objetivos entre o corpo permanente e o não permanente de trabalhadores.

Se, por um lado, o corpo não permanente apresenta problemas por não ter vivido por longos períodos de tempo na organização e não possuir uma visão do todo no serviço público onde está inserido, por outro lado, o corpo permanente, com estabilidade, como afirmou Carbone (2000), também apresenta problemas refletidos na acomodação e no descompromisso com o trabalho.

As relações de poder também são diferentes no setor público, se comparadas ao setor privado. No setor público, o gestor enfrenta pressões de diferentes grupos de interesses, tornando as relações vulneráveis a interesses pessoais de quem geralmente está no comando (CKAGNAZAROFF, 2002). Considerando tais fatores na administração pública, a forte submissão a leis administrativas tende a criar um ambiente burocratizado resultando em processos de mudança mais lentos se comparados ao setor privado.

Mesmo frente aos obstáculos culturais e estruturais já discutidos, as organizações públicas estão passando por processos de transformação, principalmente no que tange à qualificação dos seus servidores. Esse fato se deve, dentre outros fatores, ao avanço tecnológico e à crescente demanda da sociedade por serviços públicos de melhor qualidade. Como as organizações públicas não atuam num vácuo, a qualidade percebida na iniciativa privada passa a ser cobrada das organizações públicas. Da mesma forma que o indivíduo no papel de consumidor exige qualidade nos produtos $e$ nos serviços que ele usufrui, o indivíduo no papel de cidadão também se torna bastante exigente quanto aos seus direitos. Para acompanhar tais exigências, as organizações públicas têm se deparado com a necessidade de servidores mais qualificados e preparados para prestarem serviços à altura das exigências apresentadas.

A transição de uma cultura caracterizada, dentre outros aspectos, também pelo conformismo dos servidores, tem, aos poucos, dado lugar a indivíduos que, apesar de muitos obstáculos, procuram nas organizações públicas, um lugar onde exista identificação com seus valores pessoais, gerando maior satisfação e reconhecimento social. Elementos como satisfação, identificação, reconhecimento, dentre outros, ajudam a definir a qualidade dos vínculos estabelecidos entre o servidor e a organização pública.

Diante das peculiaridades encontradas nas organizações públicas, este trabalho tem como objetivo verificar a relação entre os padrões de vínculos do indivíduo estabelecidos com tais organizações. Para se chegar ao objetivo proposto, este trabalho foi organizado em partes. Primeiramente, serão apresentadas algumas teorias sobre padrões de vínculos estabelecidos entre indivíduos e organizações, a fim de mostrar o percurso teórico em que foi fundamentado este estudo. A seguir, o método apresentará a amostra da pesquisa, a coleta de dados e a forma como os dados foram tratados. Posteriormente, serão apresentados os resultados obtidos e a discussão sobre esses resultados. E, para finalizar, serão apresentadas as conclusões e as referências utilizadas para elaboração deste trabalho.

\section{Referencial Teórico}

A seguir será apresentado um panorama geral da literatura e de pesquisas que constituem o domínio dos estudos sobre vínculos do indivíduo com a organização. O objetivo é traçar o quadro teórico que serviu de base para a delimitação do objeto de estudo deste artigo.

\subsection{Vínculos do Indivíduo com a Organização}

O estudo da qualidade dos vínculos entre o indivíduo e a organização é imprescindível para o entendimento das relações estabelecidas no ambiente de trabalho. Essas relações irão interferir em diversas dimensões da dinâmica organizacional com impactos 
que podem ser positivos ou não, tanto na qualidade de vida dos indivíduos quanto na produtividade, efetividade e competitividade da organização. Quando se trata de relações entre indivíduo e trabalho, constata-se a existência de uma grande diversidade de elementos que compõem os vínculos (envolvimento, identificação, apego, satisfação, motivação, centralidade, entre vários outros), cada qual com suas peculiaridades, embora haja grande superposição e sombreamento entre tais conceitos. Para abordar os tipos de vínculos, é necessário primeiramente definir o que é vínculo. A ideia de vínculo está associada à definiçãode algo que une, amarra, ata, está associado à capacidade de criar um elo, que poderá ser mantido por algum tipo de relação de troca. (MOSCON et al., 2012)

No contexto das relações de trabalho, para que indivíduo e organização se mantenham vinculados, é necessário que ambos percebam a existência de um valor que fundamente a convicção de que valha a pena mantê-lo. Com a intenção de manter o indivíduo motivado e engajado, as organizações criam incentivos por meio de políticas de gestão, com retribuições financeiras, sociais e materiais. Como resposta, espera-se dedicação do indivíduo, contribuindo positivamente para o alcance dos objetivos da organização. Dentro das percepções de reciprocidade entre indivíduo e organização, são estabelecidos vínculos, principalmente de comprometimento. (SIQUEIRA; GOMIDE, 2004)

Depois de observar estudos iniciais acerca do comprometimento, Mowday, Porter e Steers (1982) reuniram alguns outros conceitos que foram agregados ao seu construto como uma força relativa à identificação e ao envolvimento do indivíduo com a organização. Essa força que os une é caracterizada pela aceitação de objetivos, valores organizacionais e desejo de permanência como membro, a fim de exercer esforço em benefício da organização.

Por ser um tema de grande complexidade, não se chegou ainda a um consenso sobre o conceito de comprometimento organizacional. De acordo com Tenbrunsel et al. (2002), o comprometimento é um conceito atitudinal, que pode ser observado nas respostas cognitivas e comportamentais, e não nos estímulos que o desencadeiam. Segundo Bandeira, Marques e Veiga (2000), entende-se por comprometimento o forte vínculo do trabalhador com a organização, o trabalho, a carreira, o sindicato, a profissão, dentre outros focos, que incitam uma relação de troca de energia, tanto psíquica quanto física, baseada em lealdade. Daí a importância do seu estudo para compreender alguns dos motivos que levam o trabalhador a se comportar de certa maneira no ambiente de trabalho.

Meyer e Allen (1996) desenvolveram pesquisas sobre comprometimento que se tornaram um marco para estudos posteriores. Elas se tornaram a base para um modelo chamado tridimensional, em que o comprometimento é concebido sob três enfoques: afetivo; normativo; e instrumental. Para os autores, o comprometimento pode ser gerado por diferentes processos psicossociais que, em comum, geram a disposição do indivíduo em permanecer na organização. As tradições, até então isoladas, para explicar a permanência, a rotatividade e o absenteísmo foram reunidas em um único modelo integrativo com as três bases propostas, todas elas vistas como componentes do comprometimento. É importante ressaltar que o modelo proposto pelos autores apoia-se no pressuposto de que tais processos estão presentes e cada indivíduo apresenta, sempre, níveis de comprometimento oriundos das três bases. Assim, foi aberta a possibilidade de se trabalhar com perfis ou padrões de comprometimento, identificando como os grupos de trabalhadores se aproximam em termos do peso das bases afetiva, de continuação $e$ normativa.

O enfoque afetivo do comprometimento sublinha, como seu nome claramente indica, a natureza afetiva do processo de identificação e de envolvimento do indivíduo com os objetivos e os valores da organização. Esse enfoque é reforçado pelo sentimento de lealdade, pelo desejo de permanecer na organização e de trabalhar para seu progresso. Esse é também denominado por alguns autores como comprometimento atitudinal.

Bastos (1994), de forma congruente com a perspectiva unidimensional proposta por Mowday et al. (1982), considera três dimensões como integrantes do constructo de comprometimento: uma forte crença e aceitação de valores e objetivos da organização; um forte desejo de manter o vínculo com a organização; e a intenção de esforço em favor da organização. Sob esse enfoque, ultrapassando a simples lealdade passiva, o indivíduo assume uma postura ativa, como parte da suposição de que ele deseja dar algo de si para contribuir para o sucesso e o bem-estar da organização (BASTOS, 1994). O enfoque afetivo atitudinal no vínculo 
do indivíduo com a organização tende a ser bastante forte, considerando que se alimenta e se sedimenta nos sentimentos de aceitação, de crença, de identificação e de assimilação de valores da organização. (BANDEIRA; MARQUES; VEIGA, 2000)

A força exercida pelo indivíduo, que se compromete de forma afetivo/atitudinal e o leva a um maior envolvimento com o trabalho, proporcionando maiores benefícios para organização, constitui hoje, um dos temas mais pesquisados, tanto no Brasil quanto no exterior. (DEMO, 2003)

Segundo Bastos (1996), segue-se, em termos de prioridade de pesquisa, o comprometimento instrumental, de continuação ou sidebets (trocas laterais). Esse é um vínculo de comprometimento visto como um produto de trocas efetivadas entre trabalhador $e$ organização. Becker, em 1960, a partir da teoria dos sidebets, enfatiza a avaliação por parte do trabalhador referente ao quanto investiu e ao quanto recebeu na relação com a organização, analisando perdas e ganhos para então definir sua permanência. O termo sidebets (trocas laterais) pode ser entendido como troca de algo de valor (como tempo, dinheiro, esforço), que permanece enquanto o trabalhador presta serviços para a organização ou para outra pessoa, e cessa quando a relação profissional chega ao fim, definindo-se como uma relação de permuta econômica. Nesse contexto, parece existir um processo cognitivo avaliativo. Essa avaliação, porém, não pode ser analisada como um elemento isolado, pois existem fatores sociais antecedentes que não podem ser desprezados, como as taxas de desemprego do mercado. (SIQUEIRA; GOMIDE, 2004)

Becker (1960) afirma que o comprometimento pode ser resultado de decisões conscientes ou, também, do incremento gradual de sidebets. A formação desses sidebets ocorre de acordo com valores morais que o indivíduo carrega consigo, podendo ser classificada em quatro tipos: expectativas culturais; arranjos burocráticos; ajustamentos individuais à posição social; $e$ interação face a face. As expectativas culturais levam o indivíduo a evitar penalidades e frustrações associadas à transgressão de expectativas. Os arranjos burocráticos impessoais estão relacionados à estabilidade e aos ganhos financeiros que estariam perdidos caso o indivíduo deixasse a organização. Os ajustamentos individuais para as posições sociais referem-se aos investimentos por parte tanto do indivíduo quanto da organização para mantê-lo e desenvolvê-lo nas atividades que executa. A interação face a face também ajuda a fortalecer o vínculo do indivíduo com a organização, a partir de sidebets construídos nos processos sociais.

A terceira base do comprometimento é a normativa, fundamentada inicialmente por pesquisas desenvolvidas por Weiner (1982) e Weiner e Vardi (1990). O comprometimento normativo baseia-se em um vínculo moral do trabalhador com a organização. Nesse caso, se estabelece, assim, uma relação de troca, na qual o trabalhador percebe a organização como credora, e sentindo-se em débito, retribui com seu trabalho. Os indivíduos comprometidos na base normativa comportam-se atendendo às expectativas da organização porque acreditam que é certo e moral agir assim. Esse comprometimento é visto como uma totalidade de pressões normativas internalizadas $e$ vivenciadas pelo indivíduo para agir de maneira que siga ao encontro dos objetivos e dos interesses organizacionais. Assim, os indivíduos comprometidos na base normativa engajam-se em atividades da organização pelo senso de dever, isto é, as pressões normativas internalizadas os levam a comportarem-se de forma coerente com os objetivos organizacionais.

Meyer e Allen (1996) fazem uma síntese do modelo que contempla as três dimensões, afirmando que os indivíduos comprometidos afetivamente com a organização permanecem nela porque assim o desejam; os indivíduos comprometidos instrumentalmente permanecem porque precisam da organização; e os indivíduos comprometidos normativamente permanecem na organização porque têm uma dívida para com ela. Diante das três atitudes que cercam os vínculos de comprometimento, é possível distinguir naturezas psicológicas para cada uma delas. O desejo, pertencente à base afetiva, apresenta componentes de natureza referente a sentimentos e afetos. A necessidade e o dever correspondem, respectivamente, às bases instrumental e normativa, apresentando componentes de natureza cognitiva associados a crenças sobre o papel do indivíduo na relação de troca econômica e social com a organização (SIQUEIRA; GOMIDE, 2004). Deve-se considerar, ainda, que os vínculos normativo, instrumental e afetivo não são tipos isolados de comprometimento, podendo existir simultaneamente e em proporções diferentes. Poder-se-ia pensar que o 
trabalhador apresenta tendências a um desses vínculos, dependendo do foco e do contexto onde está inserido.

O processo de vínculo desenvolve-se a partir de critérios de permanência e pode ser analisado em dois momentos: o estabelecimento do indivíduo na organização, quando ocorre a junção, e em um segundo momento, quando de sua manutenção. A análise desses dois momentos possibilita a compreensão dos tipos de vínculo e as consequências que podem gerar. Por exemplo, a rotatividade, o comportamento passivo e ativo do empregado. Alguns autores como Barbosa e Faria (2000), no entanto, consideram que a permanência do empregado em uma organização nem sempre está relacionada ao comprometimento. Muitos empregados continuam comprometidos com a organização onde trabalhavam mesmo depois de desligados dela, por outro lado, outros podem permanecer na organização sem estarem comprometidos.

Nos processos de vínculo percebem-se atitudes comportamentais de engajamento, identificação $e$ obrigação, que configuram as relações de troca, por desejo ou necessidade, e que resultam na permanência do trabalhador na organização. Nas relações de troca e permanência são percebidas diferenças de comportamento que podem configurar vínculos ativos e passivos. Em um vínculo pautado por comportamentos ativos são observadas, principalmente, atitudes de engajamento e de identificação, movidos por uma escolha espontânea baseada no desejo. Esse engajamento pode ser observado nas manifestações de sacrifício em benefício da organização, sentimentos de responsabilidade e de proatividade. Nas atitudes de identificação, é possível observar sentimentos de afiliação, ligação afetiva, crença e aceitação de valores organizacionais. Já nos vínculos pautados por comportamentos passivos, podem ser percebidas manifestações de permanência por uma relação instrumental de troca, movidos por uma necessidade, como ilustra a Figura 1. (RODRIGUES; BASTOS, 2009)



Figura 1: Vínculos Ativos e Passivos do Indivíduo com a Organização

Fonte: Adaptada de Rodrigues (2009)

Alguns componentes do vínculo, como os apresentados pela teoria dos sidebets, criam lacunas e dúvidas quanto à definição de comprometimento, quando se trata da natureza da permanência do indivíduo na organização. Os enfoques, bases e componentes do comprometimento têm ampliado a análise de suas dimensões, o que contribui para a incorporação de inúmeros comportamentos e atitudes no modelo tridimensional, desenvolvido por Meyer e Allen (1996), gerando construções teóricas confusas e ameaçando a validade de resultados pesquisados. Nesse modelo tridimensional, é possível perceber um alargamento do conceito de comprometimento, gerando confusões como imprecisão e sobreposição dos vínculos. Para diminuir essa ampliação e essa imprecisão do conceito de comprometimento, estão sendo desenvolvidas pesquisas que procuram demarcar não apenas o que é, como, também, o que não é comprometimento. (RODRIGUES; BASTOS, 2009)

Menezes (2009) afirma que existe um leque de indicadores que ajuda a definir diversas dimensões de desempenho. Um desses indicadores apresenta distinções entre o comprometimento passivo, observado na permanência do indivíduo na organização por falta de melhor oportunidade, e o comprometimento ativo que se manifesta na identificação com a organização, a partir de esforços para beneficiá-la intencionalmente. No processo de permanência do indivíduo na organização, existe uma grande diferença entre assumir comportamentos ativos que busquem beneficiar a organização e não considerar vantajoso desligar-se dela. 
Outra forma de delimitação conceitual e empírica do comprometimento organizacional é investigar outros vínculos possíveis entre trabalhador e organização, até então incluídos no conceito de comprometimento. É o caso do entrincheiramento organizacional, definido como a tendência do trabalhador de permanecer na organização devido a possíveis perdas associadas à sua saída (RODRIGUES, 2011). Sua proposição foi inspirada no construto com foco na carreira (CARSON et al., 1995) e em teorias organizacionais ligadas à permanência por necessidade (BECKER, 1960; MOWDAY et al., 1982), com a pretensão de fornecer maior precisão teórica e empírica ao vínculo, hoje tratado como comprometimento de continuação. Blau (2001) constatou a existência de semelhanças entre o conceito de comprometimento de continuação e entrincheiramento na carreira, já que ambos se referem à permanência do indivíduo na profissão por investimentos despendidos, busca da preservação psicológica ou percepção de poucas alternativas de carreira. Diante dessas afirmações, alguns autores defendem a ideia de retirar o comprometimento de continuação, já que tal comprometimento apresenta sobreposições conceituais, passando a utilizar o vínculo do entrincheiramento. (RODRIGUES; BASTOS, 2009)

Muitos trabalhadores buscam na organização apenas um lugar seguro de onde não querem sair, por considerarem altos os custos de um desligamento. Esses vínculos são denominados por Carson et al. (1995) de entrincheiramento. O conceito de entrincheiramento, originado nas trincheiras e adaptado ao contexto organizacional, sugere um lugar que protege e oferece segurança, garantindo estabilidade e manutenção do status quo dentro de uma zona de conforto para o indivíduo. A ideia é a de que a saída dessa região de conforto poderia gerar danos, fazendo com que o indivíduo, ao permanecer na organização, sinta-se preso a ela.

Os primeiros estudos sobre entrincheiramento foram analisados tendo como foco a carreira. De acordo com Carson et al. (1995), o entrincheiramento na carreira, considerado um construto multidimensional, é composto por três principais componentes: investimento na carreira; custos emocionais; e limitações de alternativas de carreira.

O investimento na carreira é, também, baseado na teoria dos sidebets de Becker (1960), no qual são considerados fatores que levam o trabalhador a permanecer na organização, porque o rompimento dessa permanência resultaria na perda de investimentos, tanto de tempo quanto financeiros, feitos até então. Os custos emocionais estão ligados, principalmente, à percepção de poucas alternativas fora do campo onde o indivíduo atua. No decorrer da vida profissional, o indivíduo investe na sua carreira de diversas formas, mobiliza recursos para sua preparação e realização, equilibrando, e, muitas vezes, arriscando tais investimentos de ordem emocional em favor de metas e objetivos. A limitação de alternativas refere-se à falta de oportunidades percebida pelo indivíduo, que faz com que ele se sinta preso ou muitas vezes acomodado em sua função. A limitação de alternativas ocorre frequentemente como consequência da limitação da idade, conhecimento e habilidades. (CARSON et al., 1995)

No que se refere ao entrincheiramento organizacional, pode-se utilizar dois dos quatro fatores apontados por Becker (1960), que são ajustamentos à posição social e aos arranjos burocráticos impessoais, acrescido da limitação de alternativas para compreensão dos motivos que levam o indivíduo a se sentir preso à organização. As três dimensões, ajustamento à posição social (APS), arranjos burocráticos impessoais (ABI) e limitações de alternativas (LA) formam o construto do entrincheiramento. O ajustamento à posição social se refere a investimentos feitos pelo indivíduo para se adequar às exigências da organização. Tais investimentos podem ser considerados como: programas de treinamento e desenvolvimento, cursos de formação para se adequar ao cargo, dentre outros processos que façam com que o indivíduo se desenvolva na organização. Na medida em que o indivíduo é treinado e desenvolvido, formal ou informalmente, ele vai alcançando um status que influencia não apenas na organização como também na sua rede de relacionamento social, fazendo com que ele seja reconhecido pela competência. O entrincheiramento nesse caso aparece diante da ameaça da perda de todo o investimento feito para chegar à posição social, caso ele saia da organização. Os arranjos burocráticos impessoais se referem à estabilidade e aos ganhos financeiros que seriam perdidos caso o indivíduo deixe a organização. A limitação de alternativas se refere ao fato de o indivíduo não perceber outras oportunidades fora da organização, sentindo-se preso. 
Os níveis de comprometimento e de entrincheiramento indicam a força e a qualidade de ligação entre o indivíduo e a organização. Indivíduos que manifestam índices altos de comprometimento apresentam fortes traços de identificação com os valores e os objetivos da organização (SCHEIBLE, 2011). Pelo comprometimento, o indivíduo se vincula à organização por um sentimento de lealdade e de desejo de permanecer nela de forma ativa, e por isso despende esforços em seu benefício. De acordo com Andrade (2008), o nível de comprometimento está relacionado às tendências de engajamento de forma mais duradoura e consistente nas atividades que o indivíduo executa. Rodrigues (2011) afirma que indivíduos com alto comprometimento tendem a demonstrar níveis de produtividade mais desejáveis, se comparados a indivíduos com nível de comprometimento baixo. Para Baiocchi e Magalhães (2004), indivíduos com esse perfil de comprometimento demonstram níveis de motivação global mais altos, não apenas relativos ao trabalho, mas à vida.

Quanto ao nível de entrincheiramento, ele pode estar relacionado com tendências para a resistência à mudança e à permanência na estabilidade. Indivíduos que manifestam índices altos de entrincheiramento fazem parte de um grupo com características diferentes de comprometimento. Indivíduos entrincheirados permanecem na organização não porque desejam, mas por medo de perderem benefícios oferecidos por ela, caso o vínculo se desfaça. Esses benefícios podem estar relacionados ao status social por trabalhar em determinada organização, ao investimento na carreira feito até então, a benefícios financeiros e, em muitos casos, à estabilidade de emprego, dentre outros. (RODRIGUES, 2011)

\section{Método}

O percurso metodológico está estruturado para apresentar o caminho delineado, a fim de atender aos objetivos propostos neste artigo. A seguir serão apresentadas as etapas utilizadas para compor este delineamento.

\subsection{Amostra}

A pesquisa se caracteriza pela natureza descritiva de corte transversal, feita em nove organizações pú- blicas prestadoras de serviços das esferas municipal, estadual e federal, totalizando 400 casos. Dentre elas, estão a Companhia de Melhoramentos da Capital (COMCAP), a Prefeitura Municipal de Florianópolis (PMF), o Conselho Regional de Corretores de Imóveis (CRECI), a Universidade do Estado de Santa Catarina (UDESC), a Secretaria Estadual da Educação (SEE), o Tribunal Regional do Trabalho $12^{\text {a }}$ Região (TRT), a Secretaria do Patrimônio da União (SPU), a Polícia Federal (PF) e o Ministério Público da União (MPU). A seguir serão apresentadas características de cada uma das organizações.

Da esfera municipal: a COMCAP é uma empresa de economia mista responsável pela coleta, transporte e tratamento de resíduos sólidos e pela limpeza dos logradouros e das vias públicas da Capital, contratada pela Prefeitura Municipal de Florianópolis, sua acionista majoritária. A COMCAP tem 40 anos de existência, um quadro de 1,4 mil empregados e a missão de prestar serviços públicos de saneamento ambiental com eficiência, qualidade e responsabilidade social. A PMF é responsável pela gestão do município e é composta pelo Gabinete do Prefeito e pela Procuradoria Geral do Município. A PMF está subdividida em seis Secretarias Executivas, 15 Secretarias Municipais e 15 órgãos ligados a ela, dentre eles a COMCAP que também participou desta pesquisa.

Da esfera estadual: o CRECI é um órgão de amplitude estadual que faz parte do Conselho Federal e tem como finalidade fiscalizar o exercício da profissão. O CRECI é constituído em autarquia, dotada de personalidade jurídica de direito público, vinculada ao Ministério do Trabalho, com autonomia administrativa, operacional e financeira. A UDESC é uma instituição pública de educação, sem fins lucrativos, com prazo de duração indeterminado, que goza de autonomia didático-científica, administrativa e de gestão financeira, disciplinar e patrimonial. A UDESC atua para garantir a indissociabilidade entre o ensino, a pesquisa e a extensão nas diversas áreas do conhecimento, comprometidos com a cidadania e a socialização do saber. A SED de Santa Catarina tem como função assessorar, coordenar e avaliar, administrativa e pedagogicamente, as unidades escolares que fazem parte dela, definindo diretrizes e estratégias que favoreçam o desenvolvimento dos alunos. Tendo como finalidade oferecer uma educação de qualidade para todos os catarinenses. $\mathrm{O}$ 
TRT $12^{\circ}$ Região tem como finalidade prestar serviço jurisdicional no âmbito trabalhista.

Da esfera Federal: o SPU tem como missão conhecer, zelar e garantir que cada imóvel da União cumpra sua função socioambiental, em harmonia com a função arrecadadora, em apoio a programas estratégicos para a nação. A PF é um órgão subordinado ao Ministério da Justiça, cuja função é exercer a segurança pública para a preservação da ordem pública e da incolumidade das pessoas e do patrimônio, sobretudo exercendo atividades de Polícia Judiciária. Cabe ressaltar que muitos cidadãos têm contato com a Polícia Federal pelo fato de ela ser o órgão responsável pela emissão de passaportes e pelo controle dos postos de fronteira. $\mathrm{O}$ MPU tem como objetivo zelar pela observância e pelo cumprimento da lei. Faz parte dos encargos do MPU a defesa do patrimônio nacional, do patrimônio público e social, do patrimônio cultural, do meio ambiente, dos direitos e dos interesses da coletividade, especialmente das comunidades indígenas, da família, da criança, do adolescente e do idoso.

A Prefeitura Municipal de Florianópolis (PMF) contou com $22,3 \%(n=89)$ participantes, a Universidade do Estado de Santa Catarina (UDESC) com 6\% $(n=24)$, o Conselho Regional dos Corretores de Imóveis de Santa Catarina (CRECI) com $6,3 \%(n=25)$, a Secretaria do Patrimônio da União de Santa Catarina (SPU-SC) com 5\% $(n=20)$, a Secretaria da Educação do Estado de Santa Catarina (SED-SC) com 12.5\% ( $n=50)$, o Ministério Público da União em Santa Catarina (MPU) com 3,3\% ( $n=13)$, a Polícia Federal de Santa Catarina com 14,5\% ( $n=58)$, o Tribunal do Trabalho e Tribunal de Justiça de Santa Catarina (TRT-SC) com 4,3\% ( $\mathrm{n}=17)$ e a Companhia Melhoramentos da Capital (COMCAP) com 26\% ( $\mathrm{n}=104)$, como mostra a Tabela 1.

Quanto ao nível de poder federal, estadual e municipal, foram 19,3\% ( $n=77$ ) da esfera federal, $24,3 \%$ $(n=97)$ da estadual e $26,3 \%(n=225)$ da municipal.

Os participantes foram classificados por sexo, estado civil, nível educacional, local de trabalho, área, nível de atuação, regime de trabalho e responsabilidade financeira. Dos 399 que identificaram o sexo, $47,8 \%$ $(n=191)$ são homens e $52 \%(n=208)$ mulheres.
Tabela 1: Amostra da população pesquisada

\begin{tabular}{|l|l|l|}
\hline Local & n. & $\%$ \\
\hline PMF & 89 & 22,3 \\
\hline UDESC & 24 & 6 \\
\hline CRECI & 25 & 6,3 \\
\hline SPU-SC & 20 & 5 \\
\hline SED-SC & 50 & 12,5 \\
\hline MPU & 13 & 3,3 \\
\hline Polícia Federal & 58 & 14,5 \\
\hline TRT-SC & 17 & 4,3 \\
\hline COMCAP & 104 & 26 \\
\hline
\end{tabular}

Fonte: Dados da pesquisa

No que tange ao estado civil, $28 \%(\mathrm{n}=112)$ eram solteiros, $48,3 \%(n=193)$ casados, $1 \%(n=4)$ viúvos, $8,8 \%(n=35)$ separados ou divorciados e $12,5 \%$ $(n=50)$ de pessoas que vivem juntas em uma relação consensual não oficializada. Dos 400 participantes, $60 \%(n=240)$ têm filhos.

Quanto ao nível educacional, $0,5 \%(n=2)$ não ultrapassaram o nível de alfabetização, 7,\% ( $\mathrm{n}=31$ ) cursaram alguns anos do ensino fundamental, $5 \%(n=20)$ possuíam ensino médio incompleto, $20,8 \%(n=83)$ ensino médio completo, $19,5 \%(n=78)$ possuíam nível superior incompleto, $23,5 \%(n=94)$ nível superior completo e $22,5 \%(n=90)$ eram pós-graduados. Do total, $15 \%(n=60)$ continuam estudando.

No que se refere à área, ela foi subdividida em área-fim e área-meio. Do total da amostra, 42,3\% $(n=169)$ estavam na área-fim e 57,3\% ( $n=229)$ na área-meio. O nível de atuação foi subdividido em estratégico, tático e operacional. No nível estratégico estavam $8,5 \%(n=34)$, no tático $49 \%(n=196)$ e no operacional $42,3 \%(n=169)$.

Quanto ao regime de trabalho, $46 \%(n=184)$ eram de estatutários, 30,5\% ( $\mathrm{n}=122)$ de celetistas, $4,8 \%(\mathrm{n}=19)$ possuíam cargos comissionados, $10,8 \%$ $(\mathrm{n}=43)$ de terceirizados e 4,3\% $(\mathrm{n}=17)$ de estagiários. Cabe ressaltar que destes, $7 \%(n=28)$ possuíam outro emprego. 
Por último, quanto à responsabilidade financeira, $25,3 \%(n=10)$ eram os únicos responsáveis financeiramente pelo sustendo da família, $21,3 \%(n=85)$ eram os principais responsáveis, $32,8 \%(\mathrm{n}=131)$ dividiam igualmente a responsabilidade financeira da família, $14,3 \%(n=57)$ contribuíam apenas com uma parte do sustento financeiro da família, e 6,3\% $(n=25)$ não tinham nenhuma responsabilidade financeira.

Diante da amostra coletada, é importante apresentar a maneira como os dados foram tratados para facilitar o entendimento dos resultados.

\subsection{Coleta de Dados}

A coleta de dados foi estipulada por amostragem por conveniência, na qual o critério de escolha foi a disponibilidade e a aceitação do indivíduo em participar da pesquisa. Em decorrência das inúmeras dificuldades de engajamento de participantes em pesquisas eletrônicas, optou-se pela coleta de dados presencial, que foi realizada no período de dezembro de 2010 a junho de 2011.

\subsection{Tratamento dos Dados}

Para o tratamento dos dados coletados foi utilizado o pacote estatístico SPSS (Statistical Package for Social Sciences) apropriado para as ciências sociais, a partir do qual foram registradas as frequências e as porcentagens das variáveis investigadas. Para analisar os vínculos de comprometimento e do entrincheriamento foram identificados quatro clusters. O método de análise a partir de clusters tem como finalidade agrupar casos com características específicas indicadas pelo pesquisador, com base em um referencial teórico. Com o intuito de dividir a amostra em clusters, foram calculadas as medianas das escalas de comprometimento $e$ de entrincheiramento apresentadas na coleta de dados, para estipular dois níveis: alto e baixo. A mediana da amostra foi de 4,3 para a escala de comprometimento e de 3,0 para a escala de entrincheiramento (escala variava de 1 a 6 ).

Os participantes que apresentaram nível de comprometimento acima de 4,3 foram considerados de comprometimento alto, os que apresentaram nível abaixo desse valor foram considerados de comprometimento baixo. Os participantes que apresentaram nível de entrincheiramento acima de 3,0 foram considerados de nível alto e os que apresentaram valores abaixo de 3,0 foram considerados de entrincheiramento baixo. Foram, então, encontrados quatro clusters: alto comprometimento e alto entrincheiramento; alto comprometimento e baixo entrincheiramento; alto entrincheiramento e baixo compromentimento; e baixo entrincheiramento e baixo comprometimento.

Dentro de cada cluster foi verificada a relação com os dados sociodemográficos referentes ao sexo, estado civil, nível educacional, local de trabalho, esfera, área, nível, regime de trabalho e grau de responsabilidade financeira.

Na sequência, serão apresentados os resultados e, a partir deles, algumas discussões consideradas relevantes para responder ao problema de pesquisa e atender aos objetivos propostos.

\section{Resultados e Discussões}

Foram encontrados quatro clusters na amostra de servidores públicos da pesquisa. No Cluster 1 , de altos níveis de comprometimento e entrincheiramento foram encontrados 30,25\% ( $n=121)$ do total da amostra. De acordo com os fundamentos discutidos na base teórica, indivíduos com esse perfil sentem-se vinculados à organização por não perceberem melhores alternativas no mercado ou por acreditarem que seu perfil profissional é limitado. Mas isso não os impede de contribuírem de forma produtiva com os objetivos da organização.

No Cluster 2, de alto nível de comprometimento e baixo nível de entrincheiramento foram incluídos $22,25 \%(n=89)$ do total da amostra. Tais indivíduos possuem forte nível de identificação com a organização, contribuindo para alcançar os objetivos organizacionais sem se sentirem presos a ela.

No Cluster 3 com nível de comprometimento baixo e de entrincheiramento alto foram incluídos $20,75 \%$ ( $n=83$ ) da amostra. Esse tipo de padrão de vínculo é caracterizado pelo sentimento de prisão à organização e, também, pelo medo de enfrentar a realidade diante de sua perda. Ao mesmo tempo em que se teme a perda do vínculo com a organização, há uma fraca identificação com ela.

No Cluster 4 de níveis de comprometimento $e$ entrincheiramento baixos foram incluídos $26,75 \%$ 
( $n=107)$ do total da amostra. Nesse padrão de vínculo, os indivíduos não se sentem presos e, tampouco, se identificam com a organização e com seus valores, como mostra a Figura 2.

A seguir serão apresentados os resultados mais relevantes, organizados por clusters, encontrados na amostra coletada.

Em relação ao estado civil, foi identificado que $37,5 \%$ são solteiros e encontram-se no Cluster 4 , de comprometimento e entrincheiramento baixos, ao passo que $35 \%$ são casados e encontram-se no Cluster 1 , de comprometimento e entrincheiramento altos, o que sugere que o estado civil pode contribuir para explicar o tipo de vínculo que o trabalhador constrói com a organização. Em congruência com esse resultado, os que têm filhos $(38,8 \%)$ estão presentes no Cluster 1 , ao passo que $37,1 \%$ dos que não têm filhos encontram-se no Cluster 4.

Em termos gerais, o Cluster 1, caracterizado pelo alto padrão de comprometimento e entrincheiramento, é composto por indivíduos casados, com filhos e com alto grau de responsabilidade financeira na manutenção da família. Esses três elementos caracterizam um indivíduo provedor com relação à família. Para indivíduos com esse perfil, a permanência no emprego é importante para dar continuidade ao sustento.

Predominantemente, como se observa no Gráfico 1 , os servidores com menor nível educacional se encontram nos Clusters 1 e 3 que, em comum, têm o elevado grau de entrincheiramento. Isso se observa entre os servidores que possuem até o ensino médio completo. Os servidores com nível superior completo ou pós-graduação, em sua maioria, encontram-se nos clusters 2 e 4 , que têm em comum o fato de agruparem servidores com baixos níveis de entrincheiramento. No entanto, enquanto os que possuem o nível superior completo, proporcionalmente, estão mais presentes no Cluster 4 (com baixo comprometimento), os pós-graduados se encontram no Cluster 2 (com alto comprometimento).

Esses dados corroboram, em parte, com os resultados da pesquisa apresentada por Botelho $e$ Paiva (2011), que também perceberam a relação entre um alto grau de comprometimento e um baixo nível educacional. De acordo com Medeiros e Albuquerque (2007), a baixa qualificação, baixa empregabilidade e

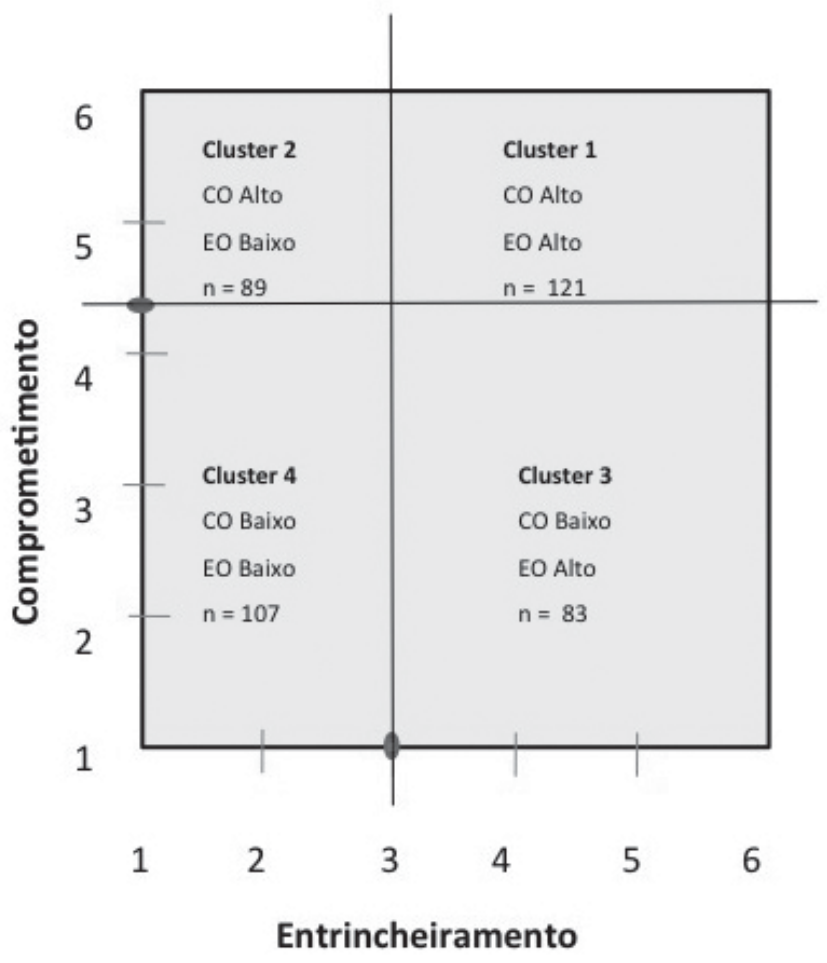

Figura 2: Divisão da Amostra por Clusters

Fonte: Elaborada pelos autores deste artigo 


\section{Nível Educacional}

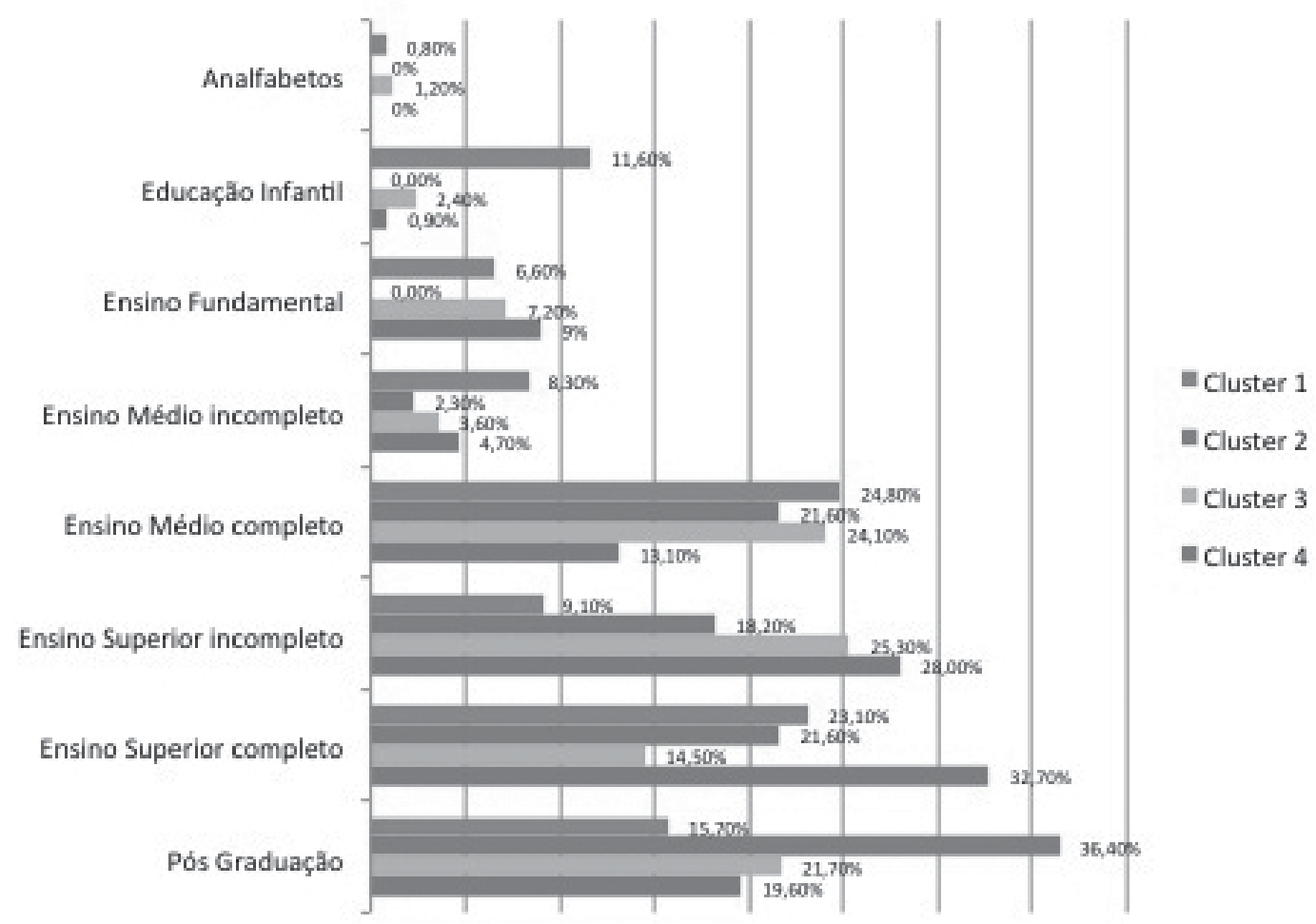

Gráfico 1: Nível Educacional por Cluster

Fonte: Elaborada pelos autores deste artigo

autoestima estão relacionadas à percepção de poucas alternativas quanto à colocação no mercado de trabalho. Os medos e as inseguranças daí decorrentes podem levar o indivíduo a se sentir mais entrincheirado, fazendo com que eles permaneçam na organização, além de outros motivos, também por medo de enfrentar o mercado, tendo em vista seu baixo nível educacional, além do fato de eles não darem continuidade aos estudos.

Quanto à esfera de atuação, percebeu-se o predomínio, na esfera federal com $33 \%$ e na municipal com $34 \%$, de indivíduos com comprometimento e entrincheiramento altos (Cluster 1). Destes, $34 \%$ dos indivíduos que trabalham na esfera estadual, no entanto, foram incluídos no cluster de comprometimento e entrincheiramento baixos (Cluster 4).

Referente à área de atuação, percebeu-se a predominância de $41 \%$ de indivíduos que trabalham na área-fim, com níveis de comprometimento e entrincheiramento altos (Cluster 1), e 34\% de indivíduos da área-meio, com níveis de comprometimento $e$ entrincheiramento baixos (Cluster 4). Quanto à lotação do trabalho, percebeu-se que indivíduos da área-fim são predominantemente mais comprometidos $e$ entrincheirados, se comparados com indivíduos da área-meio. De acordo com Coelho Junior (2007), funcionários das áreas-fim avaliam seu trabalho de maneira mais positiva do que os da área-meio. Essa característica talvez esteja relacionada com o fato de indivíduos das áreas-fim possuírem um maior nível de profissionalização por estarem mais envolvidos diretamente com aquilo que a organização se propõe a fazer (BASTOS, 1997). Esse envolvimento, além de possivelmente existir por uma maior identificação, faz com que o indivíduo tenha medo de perder o emprego, se comparado com a área-meio que tende a ser mais burocrática e menos especializada. Talvez a tendência, tanto para a área-meio quanto para o nível operacional, e pelo fato de eles serem menos especializados, crie 
no indivíduo a concepção de maior empregabilidade, já que o trabalho que executa naquela organização poderia ser executado em muitas outras.

Quanto ao nível de atuação, observou-se que $36 \%$ dos indivíduos do nível tático possuem comprometimento e entrincheiramento baixos (Cluster 4), ao passo que $38 \%$ do nível operacional possuem comprometimento e entrincheiramento altos (Cluster 1).

Referente à responsabilidade financeira, percebeu-se que quanto maior essa responsabilidade, mais os indivíduos se aproximam de níveis de comprometimento e de entrincheiramento altos, e quanto menor, mais se aproximam de níveis de comprometimento e de entrincheiramento baixos. Os indivíduos que se caracterizam como únicos ou principais responsáveis financeiramente pelo sustento da família somaram $60 \%$ inseridos no cluster de comprometimento e entrincheiramento altos (Cluster 1). Os indivíduos que dividem igualmente a responsabilidade contribuem apenas com uma parcela ou não têm nenhuma responsabilidade financeira somaram $78 \%$ no cluster de comprometimento e entrincheiramento baixos. Indivíduos com mais responsabilidade financeira, possivelmente, se sentem mais presos à organização, demonstrando mais necessidades com relação ao sustento da família $e$, com isso, apresentando níveis maiores de entrincheiramento. Esse fato pode ocorrer pelo medo de perder o emprego, já que esses indivíduos têm de permanecer no trabalho e buscam uma maior satisfação na execução das suas tarefas, aumentando, assim, o seu bem-estar no período em que ficam na organização.

O Cluster 4, caracterizado pelos baixos níveis de comprometimento e entrincheiramento, é composto, em sua maioria, por indivíduos solteiros, sem filhos e com pouca responsabilidade financeira diante da família. Talvez, por demonstrarem mais liberdade quanto às amarras familiares, tanto de ordem financeira quanto emocional, Rodrigues (2011) tenha denominado os indivíduos situados neste cluster de "transeuntes organizacionais", como pessoas que percorrem a organização sem estarem presas a ela, nem por identificação como seria no caso do comprometimento, nem por medos associados à sua saída, com seria o caso do entrincheiramento.

De uma forma geral, pode-se pensar que quanto menos compromissos o indivíduo assume com terceiros (esposa, filhos) buscando um nível de profissionali- zação aceitável, sem estar ao mesmo tempo preso a especificações do cargo, mais baixos são os níveis de comprometimento e entrincheiramento.

\section{Conclusões}

A partir dos resultados desta pesquisa foi possível identificar aspectos relevantes referentes aos vínculos estabelecidos pelos indivíduos com organizações públicas.

Os indivíduos estabelecem vínculos das mais variadas naturezas, as quais impactarão na qualidade de suas ações. Os vínculos de comprometimento alto estão associados a bons desempenhos, por outro lado, os vínculos de entrincheiramento alto estão relacionados a escores de baixo grau de desempenho e menos centralidade no trabalho. Em geral, os perfis com alto grau de comprometimento e baixo de entrincheiramento são os que mais se associam a comportamentos desejáveis em termos de produtividade e de bom desempenho nas organizações.

O arranjo dos vínculos por padrões foi anteriormente apresentado por Rodrigues (2011), porém, esta pesquisa traz de forma inédita o estabelecimento desses padrões de vínculos no contexto do serviço público.

Sobre tais padrões de vínculo, constatou-se que os servidores públicos desta amostra demonstraram níveis de comprometimento alto, no qual $52 \%$ apresentaram escore superior a 4,3, e níveis de entrincheiramento alto, no qual $51 \%$ apresentaram escore superior a 3,0. Cabe ressaltar que a mediana do escore de comprometimento foi 4,3 e do entrincheiramento foi de 3,0, definindo nesta amostra os padrões de alto e de baixo para os dois tipos de vínculo.

Diante desses resultados percebeu-se, de um lado, um forte engajamento afetivo que pode favorecer a emergência de comportamentos favoráveis às organizações públicas, de outro, se percebeu que os servidores se sentem presos, uma das características do entrincheiramento. Não se pode afirmar ao certo que isso seja decorrente da estabilidade no emprego, pois não foram detectadas diferenças significativas nos níveis de comprometimento, entrincheiramento entre servidores com diferentes regimes de trabalho. Esta é, no entanto, uma questão que pode ser explorada em investigações futuras. 
No presente estudo foram encontrados alguns resultados relevantes na relação entre padrões de vínculos e variáveis sociodemográficas. Quanto ao estado civil, número de filhos, responsabilidade financeira e nível educacional, a amostra apresentou alguns elementos passíveis de associação. Indivíduos casados, com filhos e alto grau de responsabilidade financeira, na sua maioria, foram caracterizados com níveis de comprometimento e entrincheiramento altos. Percebeu-se, ainda, que quanto maior o nível educacional, maior o nível de entrincheiramento.

Pesquisadores estão despertando sua atenção para os estudos comportamentais do servidor público. No Brasil, a literatura apresenta, ainda, certa escassez de pesquisas que ampliem a compreensão da dinâmica de vários fenômenos micro-organizacionais.

Nesta pesquisa foi analisada uma amostra expressiva de servidores públicos de diferentes órgãos, o que permitiu caracterizar a intensidade dos vínculos de comprometimento e entrincheiramento e como eles podem ser combinados pelo servidor.

A necessidade de explorar mais elementos comportamentais no contexto do serviço público pôde ser percebida durante a coleta, na qual muitos respondentes sentiram a necessidade de participar da pesquisa como forma de expressarem suas opiniões. Essas manifestações sugerem a necessidade de uma atuação mais ativa diante dos processos organizacionais no serviço público. Esse fato indica que os respondentes estão comprometidos e envolvidos com a organização.

$\mathrm{Na}$ análise dos resultados desta pesquisa foi possível perceber, também, algumas lacunas, deixando espaço para pesquisas futuras. Quanto ao estudo dos vínculos sugerem-se pesquisas de natureza qualitativa, a fim de explorar as percepções do indivíduo com a organização visando analisar os significados e os valores atribuídos às organizações públicas, ao grau de identificação e às medidas de produtividade neste segmento organizacional.

Por fim, para se chegar ao estudo das peculiaridades das organizações públicas, sugere-se que sejam realizadas pesquisas comparativas com o setor privado, a fim de perceber os aspectos organizacionais que os distingam e que sirvam de suporte para qualquer análise de cunho comportamental. Incluem-se aqui pesquisas acerca da qualidade dos vínculos estabelecidos, ressaltando a sua importância para o bom desempenho e a adaptabilidade entre esses vínculos e a organização.

\section{REFERÊNCIAS}

\section{ANDRADE, R. S. Comprometimento e}

Entrincheiramento na carreira profissional de professores universitários: examinando suas relações com o bem-estar subjetivo. p. 175. (Dissertação de Mestrado). Universidade Federal da Bahia, Brasil, 2008.

BANDEIRA, M. L.; MARQUES, A. L.; VEIGA, R. T. As dimensões múltiplas do comprometimento organizacional: um estudo na ECT/MG. Revista de Administração

Contemporânea, Curitiba, Brasil, v. 4, n. 2, p. 133-157, 2000.

BARBOSA, S. L.; FARIA, J. H. Comprometimento: uma avaliação crítica sobre a práxis organizacional. Anais, XXIV Encontro da Anpad, Florianópolis, SC, 2000.

BAIOCCHI, A. C.; MAGALHÃES, M. Relações entre processos de comprometimento e entrincheiramento e motivação vital em carreiras profissionais. Revista Brasileira de Orientação Profissional, São Paulo, Brasil, v. 5, n. 1, p. 63-69, 2004.

\section{BASTOS, A. V. B. Comprometimento no trabalho: a} estrutura dos vínculos do trabalhador com a organização, a carreira e o sindicato. (Tese de Doutorado em

Psicologia). Universidade de Brasília, Brasília, DF, Brasil, 1994.

\section{Comprometimento no trabalho: alguns}

fundamentos teóricos. Salvador: Universidade Federal da Bahia, 1996.

. Revista Organizações e Sociedade. Salvador. Escola de Administração. UFBA. Salvador, Vol 4. n.9 mai/ ago, 1997.

BECKER, H. S. Notes on the concept of commitment. The American journal of Sociology, Chicago, v. 66, p. 32-40, 1960.

BERGUE, S. T. Gestão de pessoas nas organizações públicas. Caxias do Sul: Educs, 2010. 
BLAU, G. On assessing the construct validity of two multidimensional constructs: Occupational commitment and occupational entrenchment. Human Resource Management Review, Philadelphia, v. 11, p. 279-298, 2001.

BOTELHO, R. D.; PAIVA, K. C. M. Comprometimento organizacional: um estudo no Tribunal de Justiça do Estado de Minas Gerais. RAP, Rio de Janeiro, v. 45, n 5 , p. 1.249-1.283, 2011.

BRITO, A. P. M. P.; BASTOS, A. V. B. O Schema de 'trabalhador comprometido' e gestão do comprometimento: um estudo entre gestores de uma organização petroquímica. Revista Organizações \& Sociedade, Salvador, v. 8, n. 22, 2001.

CARBONE, P. P. Cultura organizacional do setor público brasileiro: desenvolvendo uma metodologia de gerenciamento da cultura. Revista de Administração

Pública, Rio de Janeiro, v. 34, n. 2, p. 133-144, 2000.

CARSON, K. D. et al. Development and construct of a career entrenchment measure. Journal of Occupational and Organizational Psychology, London, n. 68, p. 301-320, 1995.

CKAGNAZAROFF, I. B. Reforma Gerencial e o Papel do Gestor Público: ator de mudança ou de resistência? VII Congresso Internacional Del CLAD sobre La Reforma Del Estado y de La Administracón Pública, Lisboa, Portugal, 8-11 Oct., 2002.

COELHO JUNIOR, F. A. Desempenho, Satisfação e

Suporte à Aprendizagem no Trabalho: Uma Investigação Multinível. Anais do Programa de Pós Graduação em Psicologia Social, do Trabalho e das Organizações. Brasília. Universidade de Brasília, p. 49-53, 2007.

DEMO, G. Comprometimento no trabalho: uma síntese do estado da arte e uma revisão da produção nacional. Revista rPOT, Florianópolis, 2 (3), 185-213, 2003.

FLAUZINO, D. P.; BORGES-ANDRADE, J. E.

Comprometimento de Servidores Públicos e Alcance de Missões Organizacionais. RAP, Rio de janeiro, v. 42, n. 2, p. 253-273, 2008.
MEDEIROS, C. A. et al. Três (ou quatro?) componentes do comprometimento organizacional [CD]. Encontro da ANPAD, 1999, Anais..., 21, Foz do Iguaçu, PR. 1 CD, 1999.

MEDEIROS, C. A.; ALBUQUERQUE L. G.

Comprometimento organizacional: um estudo de suas relações com características organizacionais e desempenho nas empresas hoteleiras. Revista Psicologia, Florianópolis, v 5, n 2, pp 35-64, 2005.

MENEZES, I. G. Comprometimento organizacional: construindo um conceito que integre atitudes e intenções comportamentais. (Tese de Doutorado). Programa de Pós-Graduação em Psicologia. Universidade Federal da Bahia. Salvador, Bahia. 2009.

MEYER, J. P.; ALLEN, N. J. A three-component conceptualization of organizational commitment. Human Resource Mnagment Review, Ontário, Canadá. v. 1, n. 1, p. 61-89, 1991.

MEYER, J. P.; ALLEN, N. J. Affective, Continuance, and Normative Commmitment to the Organization: an Examination of Contruct Validity. Journal of Vocational Behavior, Ontário, Canadá. V. 49, p. 252276, 1996.

MOSCON, D. B; BASTOS, A.V. B.; SOUZA, J. J. É possível integrar, em um mesmo conceito, os vínculos afetivo e instrumental? O olhar dos gestores sobre o comprometimento com a organização. Revista Organizações \& Sociedade, Salvador, v. 19, n. 61, p. 357-373, 2012.

\section{MOWDAY, R. T. et al. Employee-organization}

linkages: the psychology of commitemnt, abssenteeism, and turover. New York: Academic Press, 1982.

O'REILLY, C.; CHATMAN, J. Organizational commitemnt and psychological attachment: the effects of compliance, identification, and internalizationa on prosocial behavior. Journal of Applied Psychology. V. 71, n. 3, p. 492499, 1986.

PIRES, J. C. S.; MACEDO, K. B. Cultura organizacional em organizações públicas no Brasil. Revista de Administração Pública, Rio de Janeiro, v 40 (1), ps. 81 - 105, jan/fev. 2006 
REGO, A. Comprometimento organizacional e ausência psicológica - afinal, quantas dimensões? RAE 43, São Paulo, v. 43, n. 4, ps. 25 - 35, 2003.

RODRIGUES, A. C. A.; BASTOS, A. V. B. Problemas Conceituais e Empíricos na Pesquisa sobre Comprometimento Organizacional: uma análise crítica do modelo tridimensional de J. Meyer e N. Allen. XXXIII Enontro da Anpad, São Paulo, SP, 2009.

\section{RODRIGUES, A. C. A. Do comprometimento de} continuação ao entrincheiramento organizacional: o percurso de validação da escala e análise da sobreposição entre os construtos. (Dissertação de mestrado). Universidade Federal da Bahia (UFBA), Salvador, 2009.

RODRIGUES, A. C. A. Trabalhador entrincheirado ou comprometido? Delimitação dos vínculos do indivíduo com a organização. (Tese de Doutorado em Psicologia). Universidade Federal da Bahia (UFBA), Salvador, 2011.

\section{SCHEIBLE. A. C. F. Vínculos com a organização e}

o processo de saída voluntária: teste de um modelo explicativo em uma empresa de Tecnologia da Informação (TI). (Tese de Doutorado em Psicologia), Universidade Federal da Bahia (UFBA), Salvador, 2011.

SIQUEIRA, M. M. M. Comprometimento organizacional afetivo, calculativo e normativo: Evidências acerca da validade discriminante de três medidas brasileiras [CD].

Anais... 25. Encontro da ANPAD, 2001, Campinas, SP. 1 CD, 2001.

SIQUEIRA, M. M. M.; GOMIDE, S. J. Vínculos do Indivíduo com o Trabalho e com a Organização. In: ZANELLI, J. C.; BORGES-ANDRADE, J. E.; BASTOS, A. V. B. (Org.). Psicologia, organizações e trabalho no

Brasil. Porto Alegre: Artmed, 2004.

TENBRUNSEL, A. E. et al. Cognições em organizações: handbook estudos organizacionais. São Paulo: Atlas, 2002.

VAITSMAN, J. Gerencialismo, cultura e expectativas entre servidores públicos de saúde. Revista de

Administração Pública, Rio de Janeiro, RJ, v. 35, n. 1, p. 29-47, 2001.
WEINER, Y. Commitment in organizations, a normative view. Academy of management Review, New York, v. 7, p. 418-428, 1982.

WEINER, T.; VARDI, Y. Relationship between organizational culture and individual motiationa: a conceptual integration. Psychological Reports, New York, v. 67, n. 1, p. 295-306, 1990. 